\title{
Comparison of Single and Double Stage Regenerative Organic Rankine Cycle for Medium Grade Heat Source Through Energy and Exergy Estimation
}

\author{
Ghalya Pikraa, ${ }^{a}$ and Nur Rohmah ${ }^{\mathrm{b}}$ \\ ${ }^{a}$ Research Centre for Electrical Power and Mechatronics (RCEPM) - Indonesian Institute of Sciences (IIoS) \\ Komplek LIPI, Gedung 20, Lantai 2 Jln. Sangkuriang, Bandung, West Java, Indonesia \\ ${ }^{b}$ Research Unit for Clean Technology - Indonesian Institute of Sciences (IIoS) \\ Komplek LIPI, Gedung 50, Jalan Sangkuriang, Bandung, West Java, Indonesia
}

\begin{abstract}
Regenerative organic Rankine cycle (RORC) can be used to improve organic Rankine cycle (ORC) performance. This paper presents a comparison of a single (SSRORC) and double stage regenerative organic Rankine cycle (DSRORC) using a medium grade heat source. Performance for each system is estimated using the law of thermodynamics I and II through energy and exergy balance. Solar thermal is used as the heat source using therminol 55 as a working fluid, and R141b is used as the organic working fluid. The initial data for the analysis are heat source with $200^{\circ} \mathrm{C}$ of temperature, and $100 \mathrm{l} / \mathrm{min}$ of volume flow rate. Analysis begins by calculating energy input to determine organic working fluid mass flow rate, and continued by calculating energy loss, turbine power and pump power consumption to determine net power output and thermal efficiency. Exergy analysis begins by calculating exergy input to determine exergy efficiency. Exergy loss, exergy destruction at the turbine, pump and feed heater is calculated to complete the calculation. Energy estimation result shows that DSRORC determines better net power output and thermal efficiency for $7.9 \%$ than SSRORC, as well as exergy estimation, DSRORC determines higher exergy efficiency for 7.69\%. C2019. CBIORE-IJRED. All rights reserved
\end{abstract}

Keywords: single stage regenerative organic Rankine cycle, double stage regenerative organic Rankine cycle, medium grade heat source, energy, exergy

Article History: Received July 2, 2018; Revised: March 26, 2019; Accepted: June 20, 2019; Available online: July 15, 2019 How to Cite This Article: Pikra, G. and Rohmah, N. (2019) Comparison of Single and Double Stage Regenerative Organic Rankine Cycle for Medium Grade Heat Source Through Energy and Exergy Estimation. International Journal of Renewable Energy Develeopment, 8(2), 141-148. http://dx.doi.org/10.14710/ijred.8.2.141-148

\section{Introduction}

Electricity generation systems using fossil fuels are no longer effective because its availability is increasingly depleted. In recent years, the generation of electricity using new and renewable energy sources has grown rapidly. Organic Rankine cycle (ORC) is a power generation system using new and renewable energy sources that can generate electricity at low operating temperatures. Geothermal, biomass, solar thermal, waste heat recovery, and ocean thermal energy conversion (OTEC) are some heat sources that can be applied for ORC system (Colonna et al. 2015, Rahbar et al. 2017, Li and Zhao 2016).

ORC has the same working principle as a conventional Rankine cycle system but uses an organic compound as a working fluid. This condition allows the ORC produces electricity at low temperatures. The organic compound is a working fluid that has a lower boiling point and a higher molecular mass than water that is commonly used as a working fluid in a conventional Rankine cycle (Zhai et al. 2016, Vivian et al. 2015, Cammarata et al. 2014). ORC has a simple structure characteristic, easy maintenance, high reliability, and environmental-friendly (Feng et al. 2017, Li 2016).

The heat source for ORC system is divided into three grades, including low grade $\left(<150^{\circ} \mathrm{C}\right)$, medium grade $\left(150^{\circ} \mathrm{C}-250^{\circ} \mathrm{C}\right)$, and high grade $\left(250^{\circ} \mathrm{C}-400^{\circ} \mathrm{C}\right)($ Colonna et al. 2015, Rahbar et al. 2017). In the range of temperature heat source from $80^{\circ} \mathrm{C}$ to $300^{\circ} \mathrm{C}$, ORC has low performance (Braimakis and Karellas 2018a). Many researchers have been analyzed and applied the improvement of ORC performance. Astolfi et al. analyzed optimization system performance supercritical and subcritical of ORC for low-medium geothermal heat sources $\left(120^{\circ} \mathrm{C}-180^{\circ} \mathrm{C}\right)$ (Astolfi et al. 2014). Xi et al. optimized regenerative ORC using basic, single and double stage organic Rankine cycle using low-grade waste

\footnotetext{
*Corresponding author: ghalya30@gmail.com; ghal001@lipi.go.id
} 
heat recovery. The result shows that DRORC always gives the highest thermal and exergy efficiency using any working fluid (Xi et al. 2013). Chaiyat et al. increased ORC efficiency using absorption and adsorption system. Investigation shows that ORC adsorption system can increase efficiency more than absorption system (Chaiyat et al. 2017). Li et al. optimized performance of single and dual pressure evaporation ORC. The result shows that net power output of dual pressure generally increases as the working fluid temperature increases ( $\mathrm{Li}$ et al. 2018). Imran et al. optimized regenerative ORC for waste heat recovery through economic analysis. The analysis shows that evaporation pressure influences thermal efficiency and specific investment cost (Imran et al. 2014). Braimakis et al. analyzed exergetic optimization of double stage organic Rankine cycle for waste heat recovery. The result shows that double stage ORC can rise exergy efficiency by up to $25 \%$ than single stage ORC (Braimakis and Karellas 2018b). Ge et al. performed thermodynamic analysis of ORC driven by low-temperature flue gas waste heat. The result shows that the utilization of regenerator always increase the flue gas temperature at vapor generator output, yet reduces net power output (Ge et al. 2015).

This paper presents a comparison of single and double stage regenerative organic Rankine cycle using heat source at medium grade through energy and exergy estimation. Energy and exergy estimation were carried out based on the law of thermodynamics I and II. Net power output, thermal and exergy efficiency of each system is determined to estimate the best performance. Solar thermal is used as the heat source with therminol 55 as working fluid and R141b as the organic working

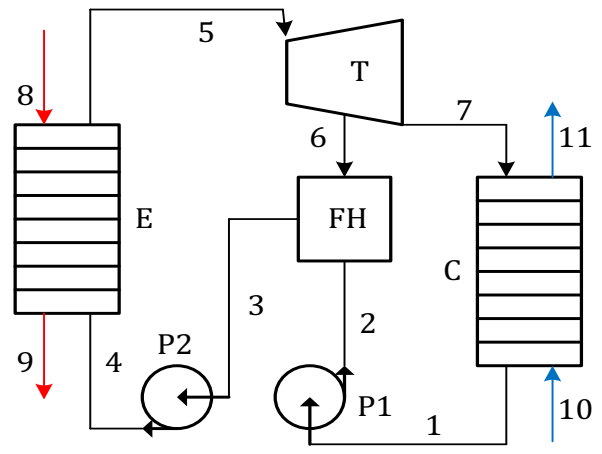

$\mathrm{E}=$ Evaporator $\quad \mathrm{C}=$ Condenser $\quad \mathrm{P} 1=$ Pump 1

$\mathrm{T}=$ Turbine $\quad \mathrm{FH}=$ Feed Heater $\quad \mathrm{P} 2=$ Pump 2

(a)

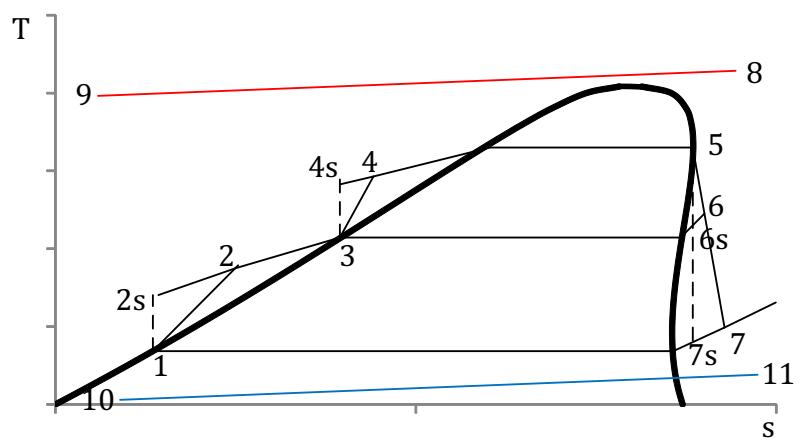

(b) fluid. Temperature and volume flow rate of the heat source is assumed $200^{\circ} \mathrm{C}$ and $100 \mathrm{l} / \mathrm{min}$.

\section{Methodology}

Improvement in organic Rankine cycle (ORC) is necessary to increase the system performance. Regenerative ORC can improve the system performance over basic ORC (Moloney et al. 2017). Single (SSRORC) and double (DSRORC) stage of regenerative organic Rankine cycle are two from many ORC modifications that are used to improve the system performance. SSRORC uses one feed heater (FH) and two pumps, while DSRORC uses two feed heater and three pumps. The schematic and T-s diagram of SSRORC and DSRORC are shown in Fig. 1.

Working principle for SSRORC is organic fluid with liquid phase is pumped to the evaporator to be heated and vaporized using heat source with medium heat grade. The vaporized organic fluid is then expanded in the turbine to generate electricity by the generator. Some organic fluid with high pressure is flowing to the feed heater to be heated by the evaporator, and some other fluid are condensed in the condenser and pumped to the feed heater for heating the liquid organic fluid before pumped to the evaporator to be vaporized. The circulation works continuously to produce electricity.

DSRORC working principle is almost the same with SSRORC. The different is some of the expanded organic fluid from the turbine is flowing into two separated feed heater, and the other fluid is condensed in the condenser. This configuration is expected to increase or improve the system performance more than SSRORC.

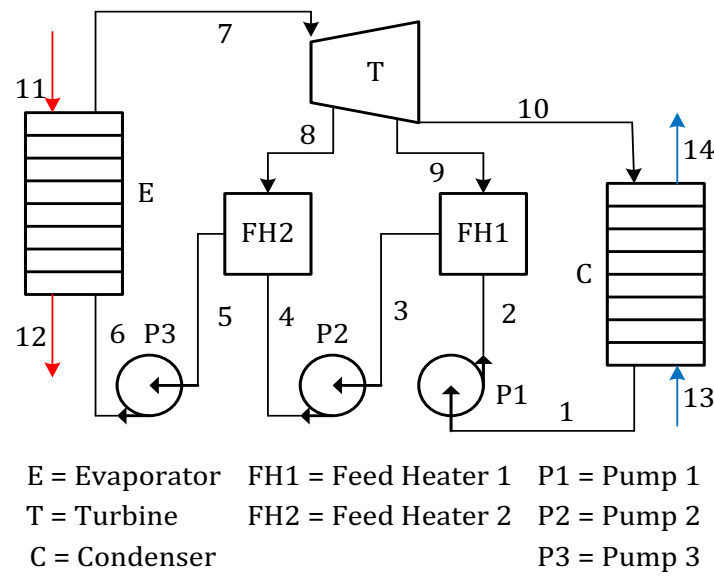

(c)

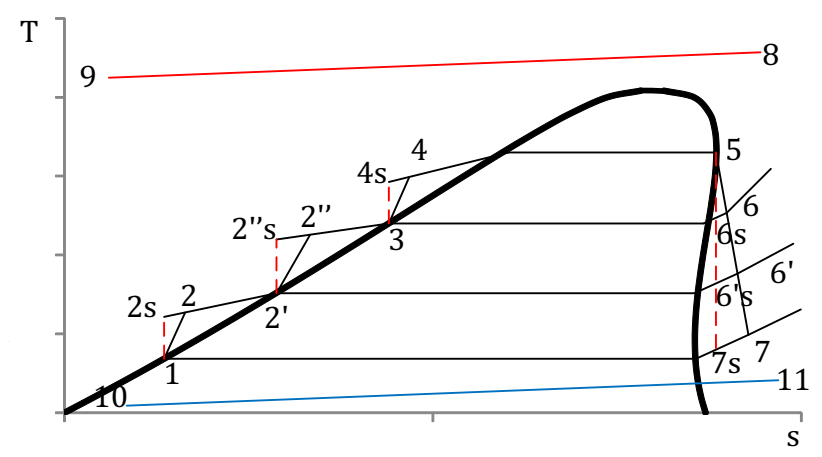

(d)

Fig. 1 (a). Schematic of SSRORC; (b) T-s diagram of SSRORC; (c) Schematic of DSRORC; (d) T-s diagram of DSRORC. 
The calculation is carried out for solar thermal with temperature and volume flow rate of $200^{\circ} \mathrm{C}$ and $100 \mathrm{l} / \mathrm{min}$, using therminol 55 as the working fluid (Stability), and $\mathrm{R} 141 \mathrm{~b}$ as the organic working fluid. Ambient and cooling fluid temperatures are assumed $25^{\circ} \mathrm{C}$ each. A temperature difference of the heat source in the evaporator and cooling fluid in the condenser is $10^{\circ} \mathrm{C}$. Organic fluid entering $\mathrm{P} 1$ and $\mathrm{P} 2$ are saturated liquid with a temperature of $35^{\circ} \mathrm{C}$ and $80^{\circ} \mathrm{C}$, and the addition of $\mathrm{P} 3$ for DSRORC is saturated liquid with a temperature of $120^{\circ} \mathrm{C}$. Organic fluid entering the turbine is saturated vapor at $190^{\circ} \mathrm{C}$ (lower than the heat source temperature for $10^{\circ} \mathrm{C}$ ). Isentropic efficiency of turbine and pump are assumed $75 \%$. The system works adiabatically, and potential and kinetic energy is negligible.

Energy and exergy balance analysis are investigated through the law of thermodynamics I and II and determined from Moran (Moran et al. 2014). The calculation begins by determining the fraction of steam extracted for each system. It is shown in equation (1) for SSRORC, equation (2) and (3) are a fraction of steam extracted for DSRORC.

$x=\frac{h_{3}-h_{2}}{h_{6}-h_{2}}$

$x=\frac{\left(h_{3}-h_{2 \prime \prime}\right)}{\left(h_{6}-h_{2 \prime \prime}\right)}$

$x^{\prime}=(1-x) \frac{\left(h_{2 \prime}-h_{2}\right)}{\left(h_{6 \prime}-h_{2}\right)}$

Where:

- $x$ is fraction of steam extracted in $\mathrm{FH}$

- $x^{\prime}$ is fraction of steam extracted in $\mathrm{FH}^{\prime}$

- $h_{2}$ is enthalpy inlet FH for SSRORC/ inlet FH' for DSRORC/ outlet P1 (kJ/kg)

- $h_{2}$, is enthalpy outlet FH'/ inlet P2 for DSRORC $(\mathrm{kJ} / \mathrm{kg})$

- $h_{2 \prime \prime}$ is enthalpy outlet P2/ inlet FH for DSRORC $(\mathrm{kJ} / \mathrm{kg})$

- $h_{3}$ is enthalpy outlet $\mathrm{FH} /$ inlet P2 for SSRORC/ inlet P3 for DSRORC $(\mathrm{kJ} / \mathrm{kg})$

- $h_{6}$ is enthalpy outlet turbine/ inlet $\mathrm{FH}(\mathrm{kJ} / \mathrm{kg})$

- $h_{6}$, is enthalpy outlet turbine/ inlet FH' for DSRORC (kJ/kg).

Energy balance for SSRORC is the same with DSRORC, where heat input $\left(Q_{E}\right)$ is equal to the sum of net power output $\left(W_{\text {net }}\right)$ and heat loss $\left(Q_{C}\right)$. Equation (1) is shown $Q_{E}$ calculation.

$Q_{E}=W_{n e t}+Q_{C}=\dot{m}_{o f}\left(h_{5}-h_{4}\right)=\dot{m}_{h} C p_{h} \Delta T_{h}=q_{h} \rho_{h} C p_{h} \Delta T_{h}$

Where:

- $\dot{m}_{o f}$ is organic fluid mass flow rate $(\mathrm{kg} / \mathrm{s})$

- $h_{4}$ is enthalpy inlet evaporator/ outlet P2 (kJ/kg)

- $h_{5}$ is enthalpy inlet turbine/ outlet the evaporator $(\mathrm{kJ} / \mathrm{kg})$

- $\dot{m}_{h}$ is heat source mass flow rate $(\mathrm{kg} / \mathrm{s})$

- $C p_{h}$ is specific heat of the heat source $\left(\mathrm{kJ} / \mathrm{kg}{ }^{\circ} \mathrm{C}\right)$

- $q_{h}$ is heat source volume flow rate $\left(\mathrm{m}^{3} / \mathrm{s}\right)$

- $\rho_{h}$ is heat source density $\left(\mathrm{kg} / \mathrm{m}^{3}\right)$
- $\Delta T_{h}$ is heat source temperature difference in the evaporator $\left({ }^{\circ} \mathrm{C}\right)$.

Heat loss in the cycle occurred in the condenser. Heat loss calculation for SSRORC and DSRORC are shown in equation (5) and (6).

$$
\begin{aligned}
& Q_{C}=\dot{m}_{o f}(1-x)\left(h_{7}-h_{1}\right)=\dot{m}_{c} C p_{c} \Delta T_{c} \\
& Q_{C}=\dot{m}_{o f}\left(1-x-x^{\prime}\right)\left(h_{7}-h_{1}\right)=\dot{m}_{c} C p_{c} \Delta T_{c}
\end{aligned}
$$

Where:

- $\quad h_{1}$ is enthalpy inlet $\mathrm{P} 1 /$ outlet condenser $(\mathrm{kJ} / \mathrm{kg})$

- $h_{7}$ is enthalpy inlet condenser/ outlet turbine $(\mathrm{kJ} / \mathrm{kg})$

- $\dot{m}_{c}$ is cooling fluid mass flow rate $(\mathrm{kg} / \mathrm{s})$

- $C p_{c}$ is specific heat of the cooling fluid $\left(\mathrm{kJ} / \mathrm{kg}{ }^{\circ} \mathrm{C}\right)$

- $\Delta T_{c}$ is cooling fluid temperature difference in the condenser $\left({ }^{\circ} \mathrm{C}\right)$.

Turbine power $\left(W_{T}\right)$ and pump power consumption $\left(W_{p}\right)$ are the next determination parameter. Calculation of $W_{T}$ for SSRORC and DSRORC are shown in equation (7) and (8), and calculation of $W_{p}$ is shown in equation (9) for SSRORC and is shown in equation (10) for DSRORC.

$W_{T}=\dot{m}_{o f} \eta_{T}\left[\left(h_{5}-h_{6 s}\right)+(1-x)\left(h_{6}-h_{7 s}\right)\right]=\dot{m}_{o f}\left[\left(h_{5}-\right.\right.$

$\left.\left.h_{6}\right)+(1-x)\left(h_{6}-h_{7}\right)\right]$

$W_{T}=\dot{m}_{o f} \eta_{T}\left[\left(h_{5}-h_{6 s}\right)+(1-x)\left(h_{6}-h_{6 \prime s}\right)\right]+[(1-x-$ $\left.\left.x^{\prime}\right)\left(h_{6 \prime}-h_{7 s}\right)\right]=\dot{m}_{o f}\left[\left(h_{5}-h_{6}\right)+(1-x)\left(h_{6}-h_{6 \prime}\right)\right]+[(1-$ $\left.\left.x-x^{\prime}\right)\left(h_{6 \prime}-h_{7}\right)\right]$

$W_{p}=\frac{\dot{m}_{o f}}{\eta_{P}}\left[(1-x)\left(h_{2 s}-h_{1}\right)+\left(h_{4 s}-h_{3}\right)\right]=\dot{m}_{o f}[(1-$ $\left.x)\left(h_{2}-h_{1}\right)+\left(h_{4}-h_{3}\right)\right]$

$W_{p}=\frac{\dot{m}_{o f}}{\eta_{P}}\left[\left(1-x-x^{\prime}\right)\left(h_{2 s}-h_{1}\right)+(1-x)\left(h_{2 \prime \prime s}-h_{2 \prime}\right)+\right.$ $\left.\left(h_{4 s}-h_{3}\right)\right]=\dot{m}_{o f}\left[\left(1-x-x^{\prime}\right)\left(h_{2}-h_{1}\right)+(1-x)\left(h_{2 \prime \prime}-\right.\right.$ $\left.\left.h_{2},\right)+\left(h_{4}-h_{3}\right)\right]$

(10)

Where:

- $\eta_{T}$ is turbine isentropic efficiency

- $\eta_{P}$ is pump isentropic efficiency

- $h_{2 s}$ is enthalpy isentropic inlet $\mathrm{FH}$ for $\mathrm{SSRORC/} \mathrm{inlet}$ $\mathrm{FH} 1$ for DSRORC/ outlet P1 (kJ/kg)

- $h_{2, s}$ is enthalpy isentropic outlet P2/ inlet FH2 for DSRORC $(\mathrm{kJ} / \mathrm{kg})$

- $h_{4 s}$ is enthalpy isentropic inlet evaporator/ outlet P2 $(\mathrm{kJ} / \mathrm{kg})$

- $h_{6 s}$ is enthalpy isentropic outlet turbine/ inlet FH for $\mathrm{SRORC/} \mathrm{inlet} \mathrm{FH2} \mathrm{for} \mathrm{DSRORC}(\mathrm{kJ} / \mathrm{kg})$

- $h_{6 / s}$ is enthalpy isentropic outlet turbine/ inlet FH1 for DSRORC (kJ/kg)

- $h_{7 s}$ is enthalpy isentropic inlet condenser/ outlet turbine $(\mathrm{kJ} / \mathrm{kg})$.

The equation of net power output $\left(W_{\text {net }}\right)$ and thermal efficiency $\left(\eta_{t h}\right)$ of the system for SSRORC and DSRORC are the same and are the last calculation in energy 
analysis. The calculation was carried out using equation (11).

$\eta_{t h}=\frac{W_{n e t}}{Q_{E}}=\frac{W_{T}-W_{P}}{Q_{E}}$

Exergy balance for SSRORC is the same with DSRORC, where exergy input $\left(E x_{E}\right)$ is equal to the sum of net power output $\left(W_{\text {net }}\right)$, exergy loss $\left(E x_{C}\right)$, exergy destruction in the turbine $\left(\dot{I}_{T}\right)$, pump $\left(\dot{I}_{p}\right)$, and feed heater $\left(\dot{I}_{F H}\right)$. The calculation is shown in equation (12).

$E x_{E}=W_{n e t}+E x_{C}+\dot{I}_{T}+\dot{I}_{p}+\dot{I}_{F H}=\dot{m}_{o f}\left[h_{5}-h_{4}-T_{0}\left(s_{5}-\right.\right.$ $\left.\left.S_{4}\right)\right]$

Where:

- $T_{0}$ is the ambient temperature $\left({ }^{\circ} \mathrm{C}\right)$

- $s_{4}$ is entropy inlet evaporator/ outlet P2 (kJ/kg)

- $s_{5}$ is entropy inlet turbine/ outlet the evaporator $(\mathrm{kJ} / \mathrm{kg})$.

Exergy loss in the system occurred in the condenser. Its calculation is shown in equation (13) for SRORC and is shown in equation (14) for DSRORC.

$E x_{C}=\dot{m}_{o f}(1-x)\left[h_{7}-h_{1}-T_{0}\left(s_{7}-s_{1}\right)\right]$

$E x_{C}=\dot{m}_{o f}\left(1-x-x^{\prime}\right)\left[h_{7}-h_{1}-T_{0}\left(s_{7}-s_{1}\right)\right](\mathbf{1 4})$

Where:

- $s_{1}$ is entropy inlet $\mathrm{P} 1 /$ outlet condenser $(\mathrm{kJ} / \mathrm{kg})$

- $s_{7}$ is entropy inlet condenser/ outlet turbine $(\mathrm{kJ} / \mathrm{kg})$.

Exergy destruction in the turbine $\left(\dot{I}_{T}\right)$ is shown in equation (15) for SSRORC and is shown in equation (16) for DSRORC. Equation (17) and (18) are shown exergy destruction in the pump $\left(\dot{I}_{p}\right)$ for SSRORC and DSRORC. Exergy destruction in the feed heater $\left(\dot{I}_{F H}\right)$ is shown in equation (19) and (20) for SSRORC and DSRORC.

$\dot{I}_{T}=\dot{m}_{o f} T_{0}\left[\left(s_{6}-s_{5}\right)+(1-x)\left(s_{7}-s_{6}\right)\right]$

$\dot{I}_{T}=\dot{m}_{o f} T_{0}\left[\left(s_{6}-s_{5}\right)+(1-x)\left(s_{6 \prime}-s_{6}\right)\right]+[(1-x-$

$\left.\left.x^{\prime}\right)\left(s_{7}-s_{6 \prime}\right)\right]$

$\dot{I}_{p}=\dot{m}_{o f} T_{0}\left[(1-x)\left(s_{2}-s_{1}\right)+\left(s_{4}-s_{3}\right)\right]$

$\dot{I}_{p}=\dot{m}_{o f} T_{0}\left[\left(1-x-x^{\prime}\right)\left(s_{2}-s_{1}\right)+(1-x)\left(s_{2 \prime \prime}-s_{2 \prime}\right)+\left(s_{4}-\right.\right.$ $\left.\left.s_{3}\right)\right]$

$\dot{I}_{F H}=\dot{m}_{o f} T_{0}\left[s_{3}-x s_{6}-(1-x) s_{2}\right]$

$\dot{I}_{F H}=\dot{m}_{o f} T_{0}\left\{\left[(1-x) s_{2}-x^{\prime} s_{6}-\left(1-x-x^{\prime}\right) s_{2}\right]+\left[s_{3}-\right.\right.$ $\left.\left.x s_{6}-(1-x) s_{2 \prime \prime}\right]\right\}$

Where:

- $s_{2}$ is entropy inlet FH for SSRORC/ inlet FH 1 for DSRORC/ outlet P1 (kJ/kg)

- $s_{2}$, is entropy outlet FH1/ inlet P2 for DSRORC $(\mathrm{kJ} / \mathrm{kg})$

- $s_{2 \prime \prime}$ is entropy outlet P2/ inlet FH2 for DSRORC $(\mathrm{kJ} / \mathrm{kg})$

- $s_{3}$ is entropy outlet FH for SSRORC/ outlet FH 2 for DSRORC/ inlet P2 for SSRORC/ inlet P3 for DSRORC $(\mathrm{kJ} / \mathrm{kg})$
- $s_{6}$ is entropy outlet turbine/ inlet $\mathrm{FH}$ for SRORC/ inlet $\mathrm{FH} 2$ for DSRORC $(\mathrm{kJ} / \mathrm{kg})$

- $s_{6}$, is entropy outlet turbine/ inlet FH1 for DSRORC $(\mathrm{kJ} / \mathrm{kg})$.

Exergy efficiency $\left(\eta_{e x}\right)$ of SSRORC and DSRORC have the same equation and is calculated through eq. (21).

$\eta_{e x}=\frac{W_{n e t}}{E x_{E}}=\frac{W_{T}-W_{P}}{E x_{E}}$

\section{Result and Discussion}

\subsection{State Analysis}

SSRORC has 6 components, including 1 evaporator, 1 turbine, 1 condenser, $1 \mathrm{FH}$, and 2 pumps, so it obtains 7 states, including state 1, 2, 3, 4, 5, 6, and 7 (see Fig. 1 (a)). While DSRORC has 8 components (10 states), including 1 evaporator, 1 turbine, 1 condenser, $2 \mathrm{FH}$, and 3 pumps. The 10 states are 1, 2, 2', 2", 3, 4, 5, 6, 6', and 7 (see Fig. 1 (c)). Fig. 2 and Fig. 3 are shown enthalpy and entropy value for each system.

Fig. 2 and Fig. 3 show that $h_{1}, h_{2}, s_{1}$, and $s_{2}$ have the same value for each system because they have the same assumption where organic fluid entering $\mathrm{P} 1$ is in saturated liquid phase. $h_{5}$ and $s_{5}$ for both system also have the same value because they have the same heat source temperature.

$h_{3}$ and $s_{3}$ for each system have a different value, where DSRORC has a higher value than SSRORC because SSRORC has lower pressure and temperature than DSRORC in state 3. SSRORC has lower pressure and temperature than DSRORC because the organic fluid in SSRORC is flowing from $1 \mathrm{FH}$, while DSRORC is flowing from $2 \mathrm{FH}$. $1 \mathrm{FH}$ allows the pressure and temperature organic fluid inlet $\mathrm{P} 2$ gain low pressure and temperature. Otherwise, $2 \mathrm{FH}$ allow the pressure and temperature organic fluid inlet P3 gain high value.

$h_{4}$ and $s_{4}$ in SSRORC gain lower value than DSRORC. Although they have the same pressure, the temperature for SSRORC is lower than DSRORC. It caused by $1 \mathrm{FH}$ that is used in SSRORC than $2 \mathrm{FH}$ in DSRORC. Thus allows enthalpy and entropy gain higher value for DSRORC than SSRORC.

$h_{6}$ in DSRORC gain higher value than SSRORC because of higher pressure and temperature. However, $s_{6}$ in DSRORC gain slightly lower value than SSRORC. $h_{7}$ and $s_{7}$ in SSRORC gain slightly higher value than DSRORC because of higher temperature, although they have the same pressure.

\subsection{The fraction of steam extracted analysis}

SSRORC has $1 \mathrm{FH}$, so it has 1 fraction of steam extracted, while DSRORC has $2 \mathrm{FH}$ which resulted in 2 fractions of steam extracted in the system. Table 1 is shown a fraction of steam extracted for each system.

Table 1

The fraction of steam extracted

\begin{tabular}{ccc}
\hline $\begin{array}{c}\text { The fraction of steam } \\
\text { extracted }\end{array}$ & SSRORC & DSRORC \\
\hline $\boldsymbol{x}$ & 0.205 & 0.227 \\
$\boldsymbol{x}^{\prime}$ & - & 0.160 \\
\hline
\end{tabular}


Table 1 is shown that SSRORC gains lower $x$ than DSRORC because it works in a lower pressure than DSRORC. While FH' in DSRORC is working in the same pressure like $\mathrm{FH}$ in SSRORC. The fraction of steam extracted influences the number of organic fluid mass flow rate that is flowing in every component of the system. This condition influences the value of each component and will influence the performance of each system in energy and exergy analysis.
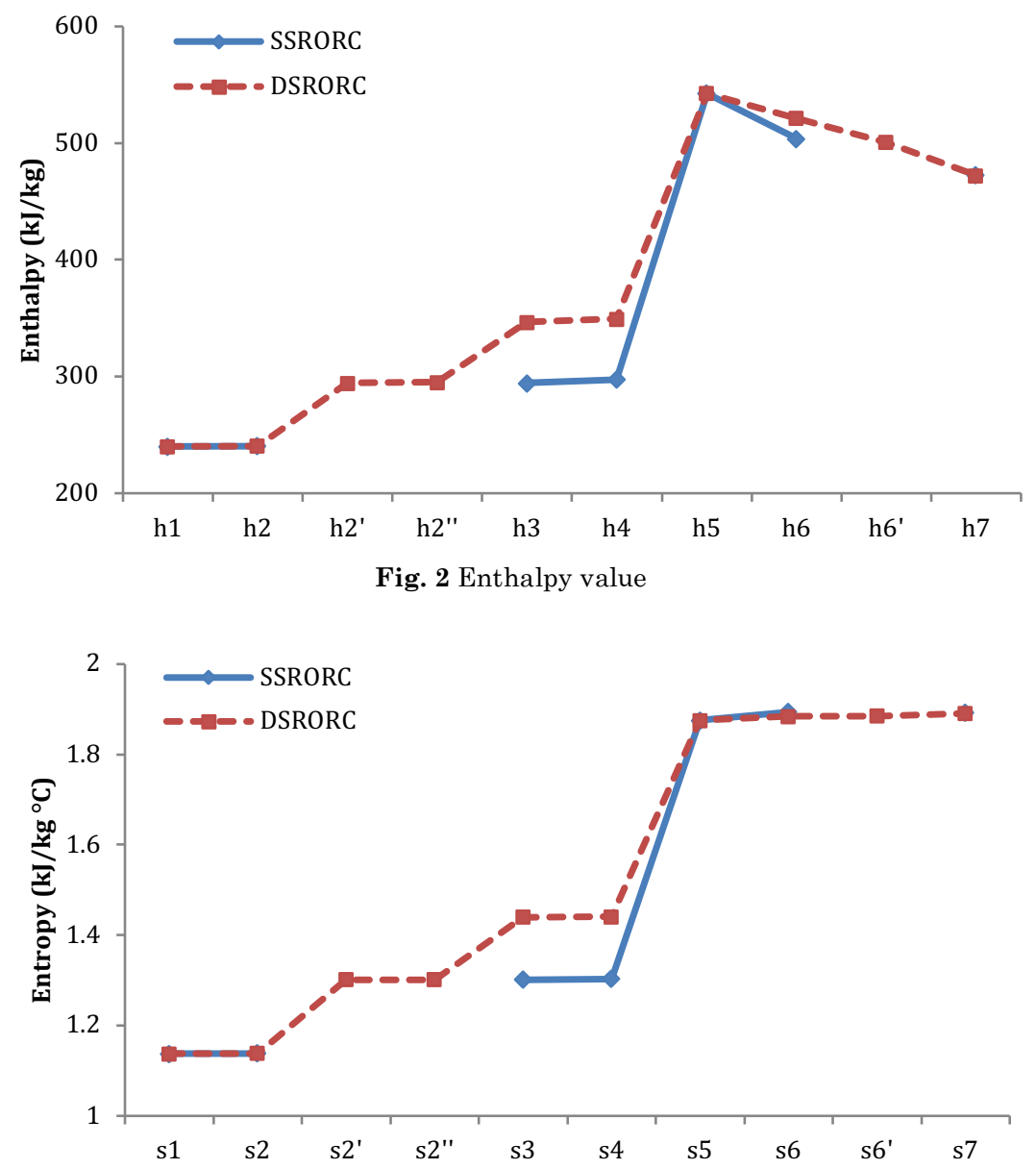

Fig. 3 Entropy value

\subsection{Energy analysis}

The result for energy analysis of SSRORC and DSRORC is shown in Table 2.

Table 2

Result for energy analysis

\begin{tabular}{lcc}
\multicolumn{1}{c}{ Parameter } & SSRORC & DSRORC \\
\hline$Q_{E}(\mathrm{~kW})$ & 31.340 & 31.340 \\
$\dot{m}_{o f}(\mathrm{~kg} / \mathrm{s})$ & 0.128 & 0.162 \\
$Q_{C}(\mathrm{~kW})$ & 23.670 & 23.064 \\
$W_{T}(\mathrm{~kW})$ & 8.099 & 8.828 \\
$W_{p}(\mathrm{~kW})$ & 0.429 & 0.551 \\
$W_{\text {net }}(\mathrm{kW})$ & 7.670 & 8.276 \\
$\eta_{T h}(\%)$ & 24.47 & 26.41 \\
\hline
\end{tabular}

Heat input/ evaporator capacity $\left(Q_{E}\right)$ in Table 2 is shown the same result for both systems. It caused by the same temperature and volume flow rate of the heat source, thus made them have the same properties (density, $\rho_{h}$, and specific heat, $C p_{h}$ ).

Organic fluid mass flow rate $\left(\dot{m}_{o f}\right)$ is influenced by heat input $\left(Q_{E}\right)$ and enthalpy difference in the evaporator $\left(h_{5}-h_{4}\right)$. Fig. 4 shows that $\left(h_{5}-h_{4}\right)$ for DSRORC gain lower value than SSRORC. The same $h_{5}$ and lower $h_{4}$ (see Fig. 2) determine higher $\left(h_{5}-h_{4}\right)$ for SSRORC than DSRORC. The same $Q_{E}$ and lower $\left(h_{5}-h_{4}\right)$ obtain higher $\dot{m}_{o f}$ for DSRORC than SSRORC (see Table 2).

Table 2 shows that heat loss $\left(Q_{C}\right)$ for SSRORC obtains slightly higher value than DSRORC. Equation (5) and (6) show that $Q_{C}$ influences by $\dot{m}_{o f}$ and $\left(h_{7}-h_{1}\right)$. Lower $\dot{m}_{o f}$, $1 \mathrm{FH}$ addition and slightly higher $\left(h_{7}-h_{1}\right)$ determine slightly higher $Q_{C}$ for SSRORC than DSRORC (see Fig. 4). The same $h_{1}$ and higher $h_{7}$ (see Fig. 2) for SSRORC, made it gain higher $\left(h_{7}-h_{1}\right)$ than DSRORC. Thus made it gain slightly higher $Q_{C}$ than DSRORC. The result shows that with the same heat input $\left(Q_{E}\right)$, DSRORC can reduce heat loss $\left(Q_{C}\right)$ in the system. 
DSRORC obtains higher turbine power $\left(W_{T}\right)$ than SSRORC for $9 \%$. It caused by $2 \mathrm{FH}$ additions in DSRORC than $1 \mathrm{FH}$ addition in SSRORC. This condition was signed by the enthalpy difference in the turbine that is shown in Fig. 4. SSRORC has 2 enthalpy differences $\left(\left(h_{5}-h_{6}\right)\right.$ and $\left.\left(h_{6}-h_{7}\right)\right)$, while DSRORC has 3 enthalpy differences $\left(\left(h_{5}-h_{6}\right),\left(h_{6}-h_{6 \prime}\right)\right.$, and $\left.\left(h_{6 \prime}-h_{7}\right)\right)$. Furthermore, higher $\dot{m}_{o f}$ is increasingly improved $W_{T}$ for DSRORC that obtain higher value than SSRORC.
Pump power consumption $\left(W_{p}\right)$ for DSRORC obtain higher value than SSRORC. It caused by more pumps that are used in DSRORC than SSRORC (see Fig. 1). This condition made DSRORC have three enthalpy difference $\left(\left(h_{2}-h_{1}\right),\left(h_{2 \prime \prime}-h_{2 \prime}\right)\right.$, and $\left.\left(h_{4}-h_{3}\right)\right)$ than SSRORC that only has two enthalpy difference $\left(\left(h_{2}-h_{1}\right)\right.$ and $\left.\left(h_{4}-h_{3}\right)\right)$ that can be seen in Fig. 4. Moreover, $\dot{m}_{\text {of }}$ is increasingly allowed DSRORC gain higher $W_{p}$ than SSRORC.

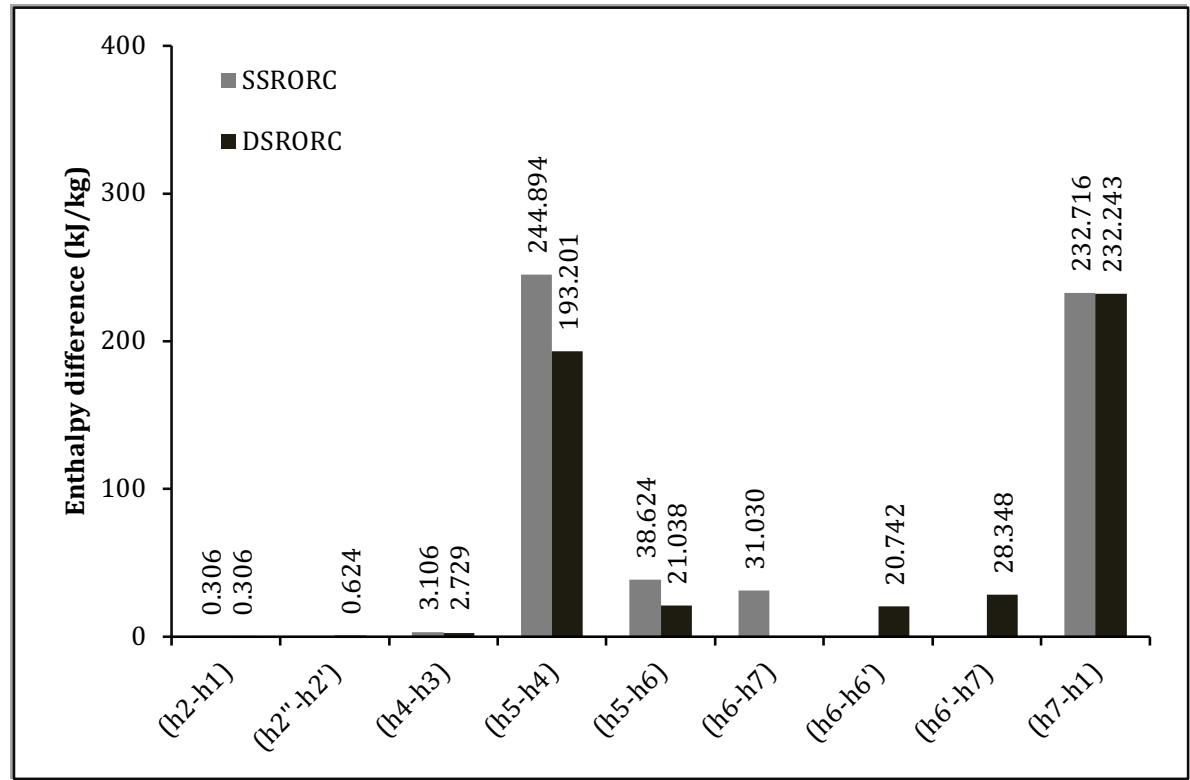

Fig. 4 Enthalpy difference value $\mathrm{s}$

Net power output $\left(W_{\text {net }}\right)$ in Table 2 shows that DSRORC gains higher value than SSRORC for 7.9\%. The difference of turbine power $\left(W_{T}\right)$ and pump power consumption $\left(W_{p}\right)$ for DSRORC is higher than SSRORC. Thus allows $W_{\text {net }}$ for DSRORC gain higher value than SSRORC. Higher $W_{\text {net }}$ and the same $Q_{E}$ cause DSRORC obtain higher thermal efficiency $\left(\eta_{t h}\right)$ than SSRORC.

\subsection{Exergy analysis}

Table 3 is shown the result for exergy analysis of SSRORC and DSRORC. Exergy input $\left(E x_{E}\right)$, exergy efficiency $\left(\eta_{e x}\right)$, exergy destruction in the pump $\left(\dot{I}_{p}\right)$ and in the feed heater $\left(\dot{I}_{F H}\right)$ for DSRORC gain higher result than SSRORC. Otherwise, exergy loss $\left(E x_{C}\right)$ and exergy destruction in the turbine $\left(\dot{I}_{T}\right)$ for DSRORC obtain lower value than SSRORC.

Table 3

Result for exergy analysis

\begin{tabular}{lcc}
\hline \multicolumn{1}{c}{ Parameter } & SSRORC & DSRORC \\
\hline $\boldsymbol{E x}_{\boldsymbol{E}}(\mathrm{kW})$ & 29.509 & 29.578 \\
$\boldsymbol{E x}_{\boldsymbol{C}}(\mathrm{kW})$ & 21.751 & 21.194 \\
$\boldsymbol{I}_{\boldsymbol{T}}(\mathrm{kW})$ & 0.056 & 0.054 \\
$\boldsymbol{I}_{\boldsymbol{p}}(\mathrm{kW})$ & 0.005 & 0.006 \\
$\dot{\boldsymbol{I}}_{\boldsymbol{F} \boldsymbol{H}}(\mathrm{kW})$ & 0.027 & 0.048 \\
$\boldsymbol{\eta}_{\boldsymbol{e x}}(\%)$ & 25.99 & 27.98 \\
\hline
\end{tabular}

Fig. 4 and Fig. 5 show that enthalpy $\left(h_{5}-h_{4}\right)$ and entropy $\left(s_{5}-s_{4}\right)$ difference in the evaporator for DSRORC gain higher result than SSRORC. DSRORC determines lower $\left(h_{5}-h_{4}\right)$ and lower $\left(s_{5}-s_{4}\right)$, although $\dot{m}_{o f}$ in DSRORC gain higher value than SSRORC. Thus obtain slightly higher $E x_{E}$ for DSRORC than SSRORC.

Exergy loss $\left(E x_{C}\right)$ of SSRORC obtains higher value than DSRORC. It caused by slightly higher enthalpy $\left(h_{7}-\right.$ $\left.h_{1}\right)$ and entropy $\left(s_{7}-s_{1}\right)$ difference in the condenser (see Fig. 4 and Fig. 5) for SSRORC than DSRORC, although SSRORC has lower $\dot{m}_{\text {of }}$ than DSRORC. This condition shows that DSRORC can increase exergy input $\left(E x_{E}\right)$ and reduce exergy loss $\left(E x_{C}\right)$ compared to SSRORC.

SSRORC obtains higher exergy destruction in the turbine $\left(\dot{I}_{T}\right)$ than DSRORC. It caused by $2 \mathrm{FH}$ additions in DSRORC than SSRORC. $2 \mathrm{FH}$ in DSRORC indicate 2 fractions of steam extracted and also show more entropy difference than SSRORC, although DSRORC has a higher $\dot{m}_{o f}$ than SSRORC. Otherwise, DSRORC gains higher exergy destruction in the pump $\left(\dot{I}_{p}\right)$ and in the feed heater $\left(\dot{I}_{F H}\right)$. It caused by 3 pumps that are added in DSRORC than only 2 pumps in SSRORC. $2 \mathrm{FH}$ that is used in DSRORC allows it obtain higher $\dot{I}_{F H}$ than SSRORC that only has $1 \mathrm{FH}$.

Equation (21) shows that exergy efficiency $\left(\eta_{e x}\right)$ is equal to the ratio of net power output $\left(W_{\text {net }}\right)$ to exergy input $\left(E x_{E}\right) . W_{\text {net }}$ for DSRORC is increased by $7.9 \%$ than SSRORC, while $E x_{E}$ for DSRORC is increased by $0.23 \%$ than SSRORC. These conditions made DSRORC gain higher $\eta_{e x}$ than SSRORC. 


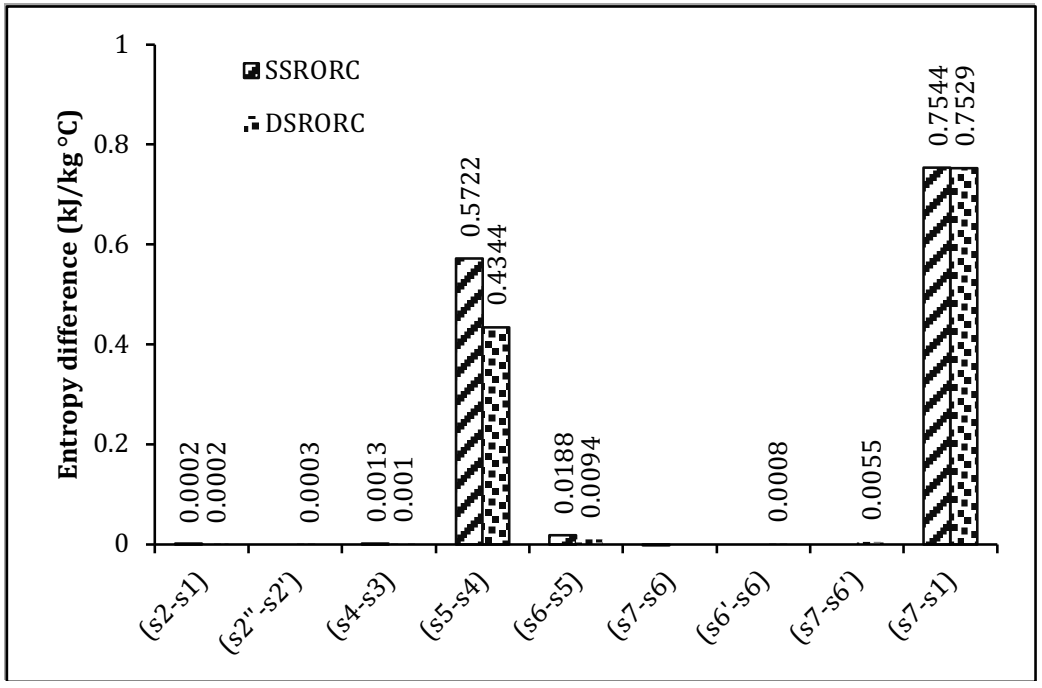

Fig. 5 Entropy difference values

\section{Conclusion}

Comparison of a single (SSRORC) and double (DSRORC) stage regenerative organic Rankine cycle using medium grade heat source concluded that DSRORC obtains higher performance than SSRORC. DSRORC determines $8.276 \mathrm{~kW}$ of net power output $\left(W_{\text {net }}\right)$, and $26.41 \%$ of thermal efficiency $\left(\eta_{t h}\right)$. It resulting in higher value for $7.9 \%$ than SSRORC. Exergy efficiency $\left(\eta_{e x}\right)$ for DSRORC obtain a higher result for $7.69 \%$ than SSRORC. The results show that more feed heater $(\mathrm{FH})$ addition in organic Rankine cycle (ORC) system determines a better performance.

\section{Acknowledgment}

The author would like to thank Dr.Eng. Budi Prawara and Dian Andriani, M.Eng for supporting the research. The author also would like to thank all researcher that has been contributed to organic Rankine cycle (ORC) research in Research Centre for Electrical Power and Mechatronics (RCEPM) - Indonesian Institute of Sciences (IIoS).

\section{References}

Astolfi, M., Romano, M. C., Bombarda, P., \& Macchi, E. (2014). Binary ORC (Organic Rankine Cycles) power plants for the exploitation of medium-low temperature geothermal sources - Part B: Techno-economic optimization. Energy, 66, 435-446.

Braimakis, K., \& Karellas, S. (2018a). Energetic optimization of regenerative Organic Rankine Cycle (ORC) configurations. Energy Conversion and Management, 159, 353-370.

Braimakis, K., \& Karellas, S. (2018b). Exergetic optimization of double stage Organic Rankine Cycle (ORC). Energy, 149, 296-313.

Cammarata, G., Cammarata, L., \& Petrone, G. (2014). Thermodynamic analysis of ORC for energy production from geothermal resources. Energy Procedia, 45, 1337-1343.

Chaiyat, N., Wakaiyang, Y., \& Inthavideth, X. (2017). Enhancement efficiency of organic Rankine cycle by using sorption system. Applied Thermal Engineering, 122, 368379.

Colonna, P., Casati, E., Trapp, C., Mathijssen, T., Larjola, J., Turunen-Saaresti, T., \& Uusitalo, A. (2015). Organic Rankine
Cycle Power Systems: From the Concept to Current Technology, Applications, and an Outlook to the Future. Journal of Engineering for Gas Turbines and Power, 137(10), 100801.

Feng, Y.-Q., Hung, T.-C., He, Y.-L., Wang, Q., Wang, S., Li, B.-X., ... W. Zhang. (2017). Operation characteristic and performance comparison of organic Rankine cycle (ORC) for low-grade waste heat using R245fa, R123 and their mixtures. Energy Conversion and Management, 144, 153-163.

Ge, Z., Wang, H., Wang, H. T., Wang, J. J., Li, M., Wu, F. Z., \& Zhang, S. Y. (2015). Main parameters optimization of regenerative organic Rankine cycle driven by lowtemperature flue gas waste heat. Energy, 93, 1886-1895.

Imran, M., Park, B. S., Kim, H. J., Lee, D. H., Usman, M., \& Heo, M. (2014). Thermo-economic optimization of Regenerative Organic Rankine Cycle for waste heat recovery applications. Energy Conversion and Management, 87, 107-118.

Li, G. (2016). Organic Rankine cycle performance evaluation and thermoeconomic assessment with various applications part I: Energy and exergy performance evaluation. Renewable and Sustainable Energy Reviews, 53, 477-499.

Li, J., Ge, Z., Duan, Y., Yang, Z., \& Liu, Q. (2018). Parametric optimization and thermodynamic performance comparison of single-pressure and dual-pressure evaporation organic Rankine cycles. Applied Energy, 217(February), 409-421.

M. Li and B. Zhao. (2016). Analytical thermal efficiency of medium-low temperature organic Rankine cycles derived from entropy-generation analysis. Energy, 106, 121-130.

Moloney, F., Almatrafi, E., \& Goswami, D. Y. (2017). Working fluid parametric analysis for regenerative supercritical organic Rankine cycles for medium geothermal reservoir temperatures. Energy Procedia, 129, 599-606.

Moran, M. J., Shapiro, H. N., Boettner, D. D., \& Bailey, M. B. (2014). Fundamentals of Engineering Thermodynamics (8th Edition). Wiley.

Rahbar, K., Mahmoud, S., Al-Dadah, R. K., Moazami, N., \& Mirhadizadeh, S. A. (2017). Review of organic Rankine cycle for small-scale applications. Energy Conversion and Management, 134, 135-155.

Stability, T. (n.d.). Typical Physical , Chemical and Thermal Properties of Therminol 55.

Vivian, J., Manente, G., \& Lazzaretto, A. (2015). A general framework to select working fluid and configuration of ORCs for low-to-medium temperature heat sources. Applied Energy, 156, 727-746.

Xi, H., Li, M.-J., Xu, C., \& He, Y.-L. (2013). Parametric optimization of Regenerative organic Rankine cycle (ORC) for 
Citation: Pikra, G. and Rohmah, N. (2019) Comparison of Single and Double Stage Regenerative Organic Rankine Cycle for Medium Grade Heat Source Through Energy and Exergy Estimation. Int. Journal of Renewable Energy Development, 8(2), 141-148, doi.org/ijred.8.2.141-148

$\mathrm{P}$ a g e $\mid 148$

low grade waste heat recovery using genetic algorith. Energy $58,473-482$

Zhai, H., An, Q., Shi, L., Lemort, V., \& Quoilin, S. (2016).
Categorization and analysis of heat sources for organic Rankine cycle systems. Renewable and Sustainable Energy Reviews, 64, 790-805.

(C) 2019. This article is an open access article distributed under the terms and conditions of the Creative Commons Attribution (CC BY) license (http://creativecommons.org/licenses/by/4.0/). 